\title{
Video show helps in improving IYCF knowledge and practice: Experience from rural Bangladesh
}

\author{
Zakia Rahman ${ }^{1}$, Fazlur Rahman ${ }^{2}$, Aminur Rahman $^{3}$, Saidur Rahman Mashreky ${ }^{4}$ \\ ${ }^{1}$ Statistician; ${ }^{3}$ Director; Centre for Injury Prevention and Research, Bangladesh (CIPRB). ${ }^{2}$ Professor and Head of Department of \\ Epidemiology, Bangladesh University of Health Sciences (BUHS), and Executive Director, CIPRB. ${ }^{4}$ Associate Professor, \\ Department of Epidemiology, BUHS, and Director, CIPRB, Dhaka, Bangladesh.
}

\section{Abstract}

Proper Infant and young child feeding is crucial for growth and development of an infant and child under two years. In Bangladesh government has taken many initiatives for improving nutritional status of children less than two years. One of them is mass media campaign. To evaluate the effectiveness of media campaign on Infant and Young Child Feeding (IYCF) in rural Bangladesh. An ecological study was conducted in a rural setting of Bangladesh during 2011. Higher proportion of mothers in intervention area had the right knowledge on initiation of breastfeeding and right practice was also found better in intervention area $(\mathrm{p}=0.003)$. Compare to control correct knowledge of exclusive breastfeeding found significantly higher $(\mathrm{p}=0.02)$ in intervention area. Better EBF practice was found in intervention area, it was $79 \%$ and $71 \%$ in intervention and control area respectively. Compare to control area, significantly higher proportion of mothers in intervention area had correct knowledge of adequacy of breast milk till six month of child $(\mathrm{P}=0.000)$. Right knowledge regarding way of increase breast milk supply was also found significantly higher in intervention area $(\mathrm{P}=0.003)$. Correct knowledge regarding initiation of complementary feeding found significantly higher in intervention area $(\mathrm{p}=0.012)$, proportions were $53 \%$ and $41 \%$ in intervention and control area respectively. Animal food feeding practice was found higher in intervention area $(\mathrm{P}=0.015)$. Both knowledge and practices of mothers on IYCF found better in intervention area. This better effect suggests video

Keywords: IYCF, Knowledge, Practice, Video show, Bangladesh.

\section{Introduction}

Proper Infant and Young Child Feeding (IYCF) is crucial for growth and development of an infant and child under two year.s ${ }^{1}$ It is important to initiate breastfeeding within an hour of child birth and need to continue exclusive breast feeding until six months. ${ }^{1}$ To reduce infant mortality and ill health, WHO recommends that mothers first provide breast milk to their infants within one hour of birth - referred to as 'early initiation of breastfeeding'. ${ }^{2}$ Epidemiologic evidence shows a causal association between early breastfeeding and reduced infectionspecific neonatal mortality in young human infants. ${ }^{3}$

Breastfeeding till 6 months of child after birth exclusively not even water is termed as exclusive breastfeeding and initiates other nutritious foods besides breastfeeding from 181 days of child is termed as complementary feeding. ${ }^{4}$ Continued breastfeeding till six months, accompanied by sufficient quantities of nutritionally adequate, safe and appropriate solid, semi-solid and soft food also helps in ensuring good nutritional status and protects against illnesses.

Globally malnutrition is responsible for nearly half (45\%) of all deaths in children under five and is responsible for around $3 \cdot 1$ million deaths in children in this age group annually. ${ }^{6}$ Malnutrition is common among children aged 6 -24 months in developing countries and it increases the

\section{Practice Points}

- Globally malnutrition is responsible for nearly half of all deaths in children under five and is responsible for around $3 \cdot 1$ million deaths in children in this age group annually.

- Proper IYCF is crucial for growth and development of an infant and child under two years.

- Intervention resulted significant improvement on knowledge of mothers about exclusive breast feeding comparing to control area.

- Correct knowledge of adequacy of breast milk and way to increase breast milk was significantly higher in intervention area however overall rate of correct knowledge in this issue was poor in both areas.

- Mass media can be an effective intervention for improving IYCF knowledge and practice of mothers and video show can be and alternative where electric supply is not available.

risk of mortality in this age group. ${ }^{7}$ Like many of the low income countries child malnutrition is a major public health problem in Bangladesh. About $41 \%$ children of under five years of age stunted, $16 \%$ children are wasted and $36 \%$ children are underweight. ${ }^{8}$

Correspondence: Dr. Saidur Rahman Mashreky, Associate Professor, Department of Epidemiology, Bangladesh University of Health Sciences (BUHS), and Director, Centre for Injury Prevention and Research, Bangladesh (CIPRB), Dhaka-1206, Bangladesh. Email: mashreky@ciprb.com. 
There has been growing evidence of the significant impact of early initiation of breastfeeding, preferably within the first hour after birth, on reducing overall neonatal mortality. ${ }^{9}$ Exclusive breastfeeding for the first six months of life can help protect newborns and infants from different diseases, reduce the risk of mortality and promote healthy development. ${ }^{10}$ Infants who were exclusively breastfed had a significantly decreased risk of contracting at least one morbidity compared to infants who were non-exclusively breastfed. ${ }^{1}$ It has been estimated that optimal breastfeeding of children under two years of age has the potential to prevent 1.4 million deaths in children under five in the developing world annually. ${ }^{11}$

In Bangladesh $43 \%$ of neonates are breastfed within one hour of birth. ${ }^{12}$ Though breastfeeding practice is very common in Bangladesh, exclusive breastfeeding practice is only $64 \%$. Around $40 \%$ of children are receiving an adequately diverse diet and consuming iron -rich foods in their complementary foods. ${ }^{13}$ Bangladesh has made strong progress in the area of child health and now is on track to achieve Millennium Development Goal 4, i.e. reducing child mortality. ${ }^{14}$ However, country needs to go far to address the problem of child nutrition especially under two years children.

In spite of the well-recognized importance of exclusive breastfeeding, the practice is not widespread in the developing world and increase on the global level is still very modest with much room for improvement. ${ }^{15-18}$ Child nutrition programs worldwide continue to require investments and commitments to improve infant feeding practices in order to have maximum impact on children's lives. ${ }^{5}$ Community-based IYCF counseling and support can play an important role in improving these practices: it can ensure access to these services in the poorest and the most vulnerable communities with limited access to health care, and therefore become an important strategy for programming with an equity focus. ${ }^{19}$ Besides community-based counseling media plays an effective role in increasing mothers and family members' awareness regarding infant and young child feeding. ${ }^{20}$

In Bangladesh, government has taken many initiatives for improving nutritional status of children under two years. One of them is mass media campaign. ${ }^{21}$ Television is being used widely for improving the knowledge and practice of mothers related to infant and young children feeding. However many of the rural villages do not have electricity and they do not have access to television. Organizing video shows was one of the initiatives in improving knowledge and practices of mothers in dark villages. ${ }^{21}$ This study was conducted to evaluate the effectiveness of media campaign on infant and young child feeding on rural area of Bangladesh.

\section{Materials and Methods}

Study design

An ecological study was conducted to determine the effect of media intervention on IYCF knowledge and practice of mothers in rural Bangladesh. The study was conducted in Companygonj upazila of Sylhet district, Bangladesh in 2011. The upazila (sub-district) is an administrative unit comprising 300,000-400,000 population. Two unions (geographical area comprising 30,00040,000 population) Islampur east and Islampur west were selected as study area. In this selected unions, villages were identified where there was no electrical supply at household level. Among those identified dark villages, 5 were randomly selected as intervention and other 5 were selected as control area. Mothers having 0 -23 month's old children were the study population of this study. In intervention area 217 mothers and in control area 224 mothers were selected.

\section{Intervention}

Video shows were organized on IYCF practices in the intervention area and no video show was organized in the control areas. One month after intervention. IYCF knowledge and practices of mothers were evaluated.

\section{Data collection procedure}

Data was collected at household level by face to face interview. A structured pre-tested questionnaire was used as data collection instrument. Twelve data collectors and two supervisors participated in the data collection procedure.

\section{Data Analysis}

Descriptive analysis was done to present frequency and proportion of IYCF knowledge and practices of mothers. Association was measured between intervention and non intervention groups. The Chi Square test was conducted to show the statistical significance of association.

\section{Ethical considerations}

The ethical clearance for the study was obtained from the CIPRB Ethical Review Committee. A consent form was developed and utilized for each of the interview. Oral consent was taken from each of the respondents. Anonymity of each interviewee was strictly maintained. The participants of the study were informed that the collected data would be used for the research only.

\section{Results}

About 50\% mothers were illiterate and about $50 \%$ fathers were daily wage earners both in intervention and control areas. No significant difference observed between intervention and control area in other socio economic indicators.

About 93\% mothers in intervention area and 91\% mothers in control area had correct knowledge about early initiation of breastfeeding. Regarding exclusive breast feeding about $84 \%$ mothers in intervention area and $75 \%$ in control area had correct knowledge (Table $1)$. The difference is statistically significant $(p=0.0201)$. Regarding right knowledge of adequacy of breast milk till six month of child $24 \%$ in intervention area and $11 \%$ mothers in control area had correct knowledge. The difference was found significant $(p=0.000)$.

About $53 \%$ mothers in intervention area and $41 \%$ 
mothers in control area had correct knowledge about initiation of complementary feeding (Table 2). The difference is statistically significant $(p=0.012)$.

Right knowledge of mothers regarding 'how can mother increase breast milk supply' was also found significantly higher in intervention area $(P=0.003)$. Higher proportion of mother had the correct knowledge about how to increase flow of breast milk and it was $11 \%$ and $4 \%$ in intervention and control area respective (Table 1). Correct knowledge regarding quantity of complementary food in a day for 7 month to 23 month old child was found higher in intervention area compared to control $(p=0.011)$. Knowledge about food frequency per day of 7-23 month old child is also higher in intervention area than control area.

In control area about $81 \%$ mothers initiated breast feeding within correct initiation time, it was about $10 \%$ higher in intervention area (Table 2). The difference was statistically significant $(p=0.003)$. Among the study population, who had below 180 days old child, in intervention area $79 \%$ of them practiced EBF and in control area it was $71 \%$.In intervention area mothers initiated complementary feeding at 7 month of their child in a higher rate compare to control area.

It is revealed that animal food feeding practice among children aged 7 month to two year old child is higher in intervention area, which is $47 \%$ in intervention area and $34 \%$ in control area (Table 2). This was found statistically significant. ( $p=0.015)$. Higher proportion of mothers who were giving three varieties or more food to their children were found in intervention area than control area.

\section{Discussion}

The key findings of the study showed that breast feeding related knowledge and practice found significantly better in intervention area. Like many other low income countries under nutrition of children is one of the major public health problem in Bangladesh. ${ }^{8,22}$ In order to improve the situation comprehensive strategies have been developed. Both interpersonal communication and mass media campaign considered as major approach for improving IYCF knowledge and practice of mothers. Most of the TV channel has been involved in mass media campaign. However there are some places in Bangladesh where electricity hasn't yet available. In these areas people were out of contact of Television/mass media communication. In this situation organize video shows an alternative approach was considered. It is important to explore whether video show was considered as an alternative for TV broad casting. Video shows were organized in the media dark, where electric supply is unavailable. One month after organizing data were collected both from intervention and control area for comparison.

About Compare to complementary feeding practice Exclusive Breast feeding practice was found better both in intervention and control area and compare to national average. Both in intervention and control area a special maternal and child health program was ongoing and this program had breast feeding promotion component. This higher exclusive breast feeding rate may be because of effect of this existing program. However higher rate of correct knowledge and practice of breast feeding was observed in intervention area. Study conducted India show the similar effect of video show on mothers

Table 1: Distribution of mothers according to correct knowledge of breast feeding and complementary feeding

\begin{tabular}{|c|c|c|c|c|c|}
\hline \multirow[t]{2}{*}{ Breastfeeding knowledge } & \multicolumn{2}{|c|}{$\begin{array}{c}\text { Intervention } \\
(\mathrm{n}=\mathbf{2 1 7})\end{array}$} & \multicolumn{2}{|c|}{$\begin{array}{l}\text { Control } \\
(n=224)\end{array}$} & \multirow[t]{2}{*}{$p$} \\
\hline & Freq & $\%$ & Freq & $\%$ & \\
\hline Initiation of breastfeeding & 202 & 93.1 & 204 & 91.1 & 0.43 \\
\hline Exclusive breastfeeding & 183 & 84.3 & 169 & 75.4 & 0.0201 \\
\hline Adequacy of BM till 6 month & 52 & 24.0 & 25 & 11.2 & 0.000 \\
\hline Increase flow of BM & 23 & 10.6 & 8 & 3.6 & 0.003 \\
\hline Initiation of $\mathrm{CF}$ & 74 & 34.1 & 89.0 & 39.7 & 0.220 \\
\hline
\end{tabular}

Table 2: Distribution of mothers according to correct practices of breast feeding and complementary feeding

\begin{tabular}{|c|c|c|c|c|c|}
\hline \multirow[t]{2}{*}{ Breastfeeding practice } & \multicolumn{2}{|c|}{$\begin{array}{c}\text { Intervention } \\
(\mathrm{n}=\mathbf{2 1 7})\end{array}$} & \multicolumn{2}{|c|}{$\begin{array}{l}\text { Control } \\
(\mathrm{n}=224)\end{array}$} & \multirow{2}{*}{$p$} \\
\hline & Freq & $\%$ & Freq & $\%$ & \\
\hline Initiation of breastfeeding & 197 & 90.8 & 182 & 81.25 & 0.003 \\
\hline Exclusive breastfeeding & 48 & 78.7 & 37 & 71.2 & 0.355 \\
\hline Initiation of CF & 115 & 53 & 92 & 41.1 & 0.012 \\
\hline \multirow{2}{*}{$\begin{array}{c}\text { Complementary feeding } \\
\text { practice }\end{array}$} & \multicolumn{2}{|c|}{$\begin{array}{c}\text { Intervention } \\
(n=156)\end{array}$} & \multicolumn{2}{|c|}{$\begin{array}{l}\text { Control } \\
(n=172)\end{array}$} & $p$ \\
\hline & Freq & $\%$ & Freq & $\%$ & \\
\hline Took animal food & 73 & 46.8 & 58 & 33.7 & 0.015 \\
\hline Took 3 variety of foods & 72 & 46.2 & 77 & 44.8 & 0.8 \\
\hline Took 4 variety of foods & 35 & 22.4 & 35 & 20.3 & 0.64 \\
\hline
\end{tabular}


knowledge on breast feeding. ${ }^{23}$ This increases knowledge might be the effect of intervention.

Though exclusive breastfeeding rate has increased in last 10 years in Bangladesh $36.1 \%,{ }^{24} 42.9 \%{ }^{25}$ and $64.1 \%,{ }^{8}$ but this change of rate needs more improvement. A key barrier for exclusive breastfeeding might be the inadequate knowledge about breast feeding. Correct knowledge on adequacy of breast milk was found significantly higher among the mother in the intervention area. Again knowledge about process of increasing breast milk supply was also found significantly higher where video show was organized. However, overall correct knowledge is not satisfactory both in intervention and control area.

Complementary feeding practice is very poor in Bangladesh. The proportion of infants aged 6-9 months who were breastfed and received solid, semi-solid or soft foods $69.2 \%,{ }^{24} 74.2 \%{ }^{25}$ and $67.1 \%{ }^{8}$ However knowledge and practice related to quantity and frequency of complementary feeding is very poor. Our study also found poor knowledge and practice of mothers in relation to frequency and quantity of complementary feeding. Bangladesh government has taken initiatives to improve complementary feeding practice. However in our study we did not find any significant difference between intervention and control area in relation to knowledge and practice of mothers about frequency and quantity of complementary feeding. However in intervention area mother were giving animal food to their children at a significant higher rate.

The major limitation of this study is that we didn't have baseline information of IYCF knowledge and practice before conducting video shows on IYCF. However intervention and control area were very similar in characteristics. Both of the unions were in a same upazila of Bangladesh. A cross-sectional survey was conducted after one month of completion of intervention and comparison was made between the groups where video show organized and not.

\section{Conclusion}

Intervention resulted significant improvement on knowledge of mothers about exclusive breast feeding comparing to control area. Correct knowledge of adequacy of breast milk and way to increase breast milk was significantly higher in intervention area however overall rate of correct knowledge in this issue was poor in both areas. These issues need more attention for improvement, because many of the mothers failed to continue exclusive breast feeding because of this knowledge gap. Overall Knowledge and practice related to complementary feeding is poor both in intervention and control area. However, little better situation was found in intervention area. All of the finding of this study suggested video show has effect in improving mothers' knowledge and practice on IYCF. Video show can be an effective method of intervention for improving IYCF knowledge and practice place in Bangladesh where electric supply is not available.

\section{Acknowledgement}

For this study funding was provided to Alive \& Thrive by the Bill and Melinda Gates Foundation. Alive \& Thrive is managed by FHI360.

\section{References}

1. Diallo FB, Bell L, Moutquin JM, Garant MP. The efffects of exclusive versus non-exclusive breastfeeding on specific infant morbidities in Conakry (Guinea). Pan Afr Med J 2009 Apr $3 ; 2: 2$.

2. World Health Organization. Early initiation of breastfeeding. http://www.who.int/elena/titles/ early breastfeeding/en/ (accessed June 2014)

3. Edmond KM, Kirkwood BR, Amenga-Etego S, Owusu-Agyei S, Hurt LS. Effect of early infant feeding practices on infection-specific neonatal mortality: an investigation of the causal links with observational data from rural Ghana. $A m J$ Clin Nutr 2007 Oct;86(4):1126-31.

4. Butte NF, Lopez-Alarcon MG, Garza C. Nutrient adequacy of exclusive for the term infant during the first six months of life. Geneva: World Health Organization, 2002.

5. Cai X, Wardlaw T, Brown DW. Global trends in exclusive breastfeeding. Int Breastfeed $J$ 2012;7:12.

6. Maternal and Child Nutrition Study Group. Maternal and child nutrition: building momentum for impact. Lancet 2013;382(9890):372-5.

7. Zaman S, Ashraf RN, Martines J. Training in complementary feeding counselling of healthcare workers and its influence on maternal behaviours and child growth: a cluster-randomized controlled trial in Lahore, Pakistan. J Health Popul Nutr 2008;26(2):210-22.

8. NIPORT. Bangladesh Demographic and Health Survey 2011. Dhaka, NIPORT, 2013.

9. Edmond KM, Zandoh C, Quigley MA, AmengaEtego S, Owusu-Agyei S, Kirkwood BR. Delayed breastfeeding initiation increases risk of neonatal mortality. Pediatrics 2006;117(3):e3806 .

10. Akhtaruzzaman M, Khan NI, Nazrul IS. Nutrition, health and demographic survey of Bangladesh - 2011. Dhaka: Institute of Nutrition and Food Science University of Dhaka, 2013

11. Black RE, Allen LH, Bhutta ZA, Caulfield LE, de Onis M, Ezzati M, et al. Maternal and child undernutrition: global and regional exposures and health consequences. Lancet 2008;371 (9608):243-60

12. Ahmed T, Mahfuz M, Ireen S, Ahmed a MS Rahman S, Islam MM, et al. Nutrition of children and women in Bangladesh: trends and directions for the future. $J$ Health Popul Nutr 2012;30(1):1-11. 
13. Helen Keller International (HKI) and BRAC Institute of Global Health (BIGH). Food security and nutrition surveillance project round 6 : October - December 2011. Dhaka: HKI and BIGH, 2011.

14. Bhuyan AR. Millennium Development Goals (MDGs): A Review of Bangladesh's Achievements. http://ibtra.com/pdf/journal/ v2_n1_article4.pdf (accessed June 2014)

15. Senarath U, Agho KE, Akram DS, Godakandage SSP, Hazir T, Jayawickrama $\mathrm{H}$, et al. Comparisons of complementary feeding indicators and associated factors in children aged 6-23 months across five South Asian countries. Matern Child Nutr 2012;8:89-106.

16. Joshi N, Agho KE, Dibley MJ, Senarath U, Tiwari K. Determinants of inappropriate complementary feeding practices in young children in Nepal: secondary data analysis of Demographic and Health Survey 2006. Matern Child Nutr 2012;8:45-59.

17. Mihrshahi S, Kabir I, Roy SK, Agho KE, Senarath U, Dibley MJ. Determinants of infant and young child feeding practices in Bangladesh: Secondary data analysis of Demographic and Health Survey, 2004. Food Nutr Bull Japan 2010;31(2):295-313.
18. Das N, Chattopadhyay D, Chakraborty S, Dasgupta A. Infant and Young Child Feeding Perceptions and Practices among Mothers in a Rural Area of West Bengal, India. Ann Med Health Sci Res Nigeria 2013;3(3):370-5.

19. UNICEF. Community based infant and young child feeding. http://www.unicef.org/58362.html (accessed June 2014)

20. IPHN. National strategy for Infant and Young Child Feeding in Bangladesh. Dhaka: IPHN, 2007.

21. IPHN/MOH\&FW. National Communication Framework and Plan for Infant and Young Child Feeding in Bangladesh. Dhaka, IPHN, 2010.

22. Black RE, Morris SS, Bryce J. Where and why are 10 million children dying every year? Lancet 2003;361(9376):2226-34.

23. John L. A study to evaluate the effectiveness of video assisted manual teaching expression on knowledge regarding among of breastmilk postnatal mothers whose neonates are in nicu in selected hospitals at Hassan. [MSc Dissertation]. Karnatak: Rajiv Gandhi University of Health Sciences Bangalore, 2013.

24. NIPORT. Bangladesh Demographic and Health Survey 2004. Dhaka: NIPORT. 2005.

25. NIPORT. Bangladesh Demographic and Health Survey 2007. Dhaka: NIPORT, 2009. 